\title{
Autogestão: desafios políticos e metodológicos na incubação de empreendimentos econômicos solidários
}

\author{
Noëlle M. P. Lechat \\ Universidade Regional do Noroeste do Estado do Rio Grande do \\ Sul (Unijuí)
}

\author{
Eronita da Silva Barcelos \\ Universidade Regional do Noroeste do Estado do Rio Grande do \\ Sul (Unijuí)
}

\section{Autogestão: desafios políticos e metodológicos na incubação de empreendimentos econômicos solidários}

Resumo: Após sobrevoar origens históricas da autogestão na França e no Brasil, o texto questiona a capacidade de os homens se autogerirem, ou a situação de que sem chefe não há sociedade viável. Recorre a Clastres para mostrar que, se o poder político é uma necessidade inerente à vida social, ele não precisa ser hierárquico. Não há natureza humana em si, mas nossa especificidade como ser humano é justamente nossa capacidade de transformar a nós mesmos e ao mundo. Para o movimento da economia solidária brasileira, a autogestão é um conceito central, pois marca distância com as relações capitalistas, assistencialistas e acena por uma democracia radical. A autogestão possui um caráter multidimensional (social, econômico, político e técnico) e, portanto, não basta querer implantar a autogestão, ainda é preciso criar as condições para a sua efetivação. O artigo apresenta, ainda, uma reflexão sobre a metodologia autogestionária praticada pelos membros de uma incubadora universitária de economia solidária.

Palavras-chave: autogestão, economia solidária, metodologia, incubação.

\section{Self-Management: Political and Methodological Challenges to the Incubation of Solidarity Economic Enterprises}

Abstract: After reviewing the historic origins of self-management in France and Brazil, this article questions people's ability for selfmanagement, or the situation in which without a boss there is no viable society. It turns to Clastres to show that, if political power is an inherent need of social life, it does not need to be hierarchical. There is no innate human nature, but our specificity as human beings is precisely our ability to transform ourselves and the world. Self-management is a central concept of the Brazilian solidarity economics movement because it distances itself from capitalist and welfare relations and encourages radical democracy. Self-management has a multidimensional character (being social, economic, political and technical) and therefore, it is not enough to want to implant selfmanagement. It is also necessary to create the conditions for its realization. The article also reflects on the methodology of selfmanagement practiced by members of a university incubator of solidarity economics.

Key words: self-management, methodology, solidarity economy, incubation. 


\section{Um conceito político}

O presente artigo designa, como central, o caráter político da autogestão. Questiona em que medida esse princípio organizativo da vida em coletividade pode ultrapassar o ideal simbólico da autonomia humana e da democracia radical e - o mais importante - pode ser construído na prática dos grupos humanos. Termina apresentando reflexões críticas sobre uma metodologia de incubação de empreendimentos econômicos solidários que se quer autogestionária, permitindo que o homem construa o poder de autogestão da sua vida e dos grupos onde está inserido.

Antigamente, a autogestão só era pensada como fazendo parte de práticas em vigor nos países socialistas. No dicionário francês Nouveau Petit Larousse, de 1968, pode-se ler no verbete autogestão: "em alguns países socialistas, gestão de uma empresa por uma comissão de trabalhadores",", ou seja, quem escreveu o verbete nem imaginava que essa forma de gestão pudesse existir no sistema capitalista. Já no Dicionário Houaiss da Língua Portuguesa está escrito: "gerenciamento de uma empresa pelos próprios empregados, que são representados por uma direção ou por um conselho gestor." O Dicionário Aurélio do Século XXI, de maneira mais lacônica, define autogestão como: "gerência de uma empresa pelos próprios trabalhadores." Todas essas definições limitam a aplicação da autogestão à empresa. Mas, segundo Albuquerque (2003, p. 20-21), não se trata simplesmente de uma modalidade de gestão. A autogestão possui um caráter multidimensional (social, econômico, político e técnico) e refere-se a uma forma de organização da ação coletiva. A autogestão tem uma dimensão social, pois "[...] deve ser percebida como resultado de um processo capaz de engendrar ações e resultados aceitáveis para todos os indivíduos e grupos que dela dependem". Seu caráter econômico se deve às relações sociais de produção, que dão mais valor ao fator trabalho do que ao capital. Seu aspecto político baseia-se em sistemas de representação com valores, princípios e práticas favoráveis e criadoras de condições "[...] para que a tomada de decisões seja o resultado de uma construção coletiva que passe pelo poder compartilhado (de opinar e de decidir), de forma a garantir o equilíbrio de forças e o respeito aos diferentes atores e papéis sociais de cada um dentro da organização." Quanto ao aspecto técnico, ele permite pensar numa outra forma de organização e de divisão do trabalho.

O conceito de autogestão é na prática e na teoria um conceito que interpela. Primeiro, pelo seu conteúdo político; depois, pela dificuldade de ser praticado por muito tempo e, finalmente, pela polissemia do termo, que chega ser usado hoje até nas empresas capitalistas.
Nas universidades e empresas capitalistas, o termo autogestão difundiu-se com a globalização das técnicas de administração; no entanto, seu significado ainda é bastante impreciso. Algumas vezes se relaciona o referido termo com os processos produtivos de uma fábrica, outras vezes com a descrição de um fenômeno político de escolha de dirigentes, mas, de maneira geral, a autogestão está mais relacionada com métodos e técnicas administrativas. De acordo com Faria (1987) e Guimarães (1995), é possível traçar uma diferença entre as estratégias do capital (ou gerenciais) e as estratégias dos trabalhadores (LECHAT et al., 2007).

O termo autogestão significa literalmente administrar, gerir a si mesmo, do grego autos (si mesmo) e do latim gest-o, (gerir ), mas é utilizado para designar grupos que se organizam sem uma chefia. $\mathrm{O}$ princípio da autogestão parte então do pressuposto filosófico e político de que os homens são capazes de se organizarem sem dirigentes. Esse pressuposto está na base do movimento anarquista e dos movimentos libertários. Segundo Carvalho (1995, p. 27),

\section{O movimento de autogestão se originou na ala jo- vem intelectual do comunismo internacional como uma crítica da ala esquerda do bolchevismo. A es- sência dessa crítica encontra-se no admitir que qual- quer forma de socialismo sustentado por uma bu- rocracia estatal e apoiada por uma elite do partido é em si uma nova forma de capitalismo. [...] Como modelo socialista, a autogestão expressa um ideal realizado inicialmente na Comuna de Paris e nos sovietes da Revolução de Outubro.}

Desde o fim dos anos 1960, a idéia de autogoverno tornou-se, de forma crescente, assunto das discussões políticas em todas as partes do planeta. Foi introduzida, na França, para designar a experiência político-econômico-social da Iugoslávia de Tito, em ruptura ao stalinismo, e teve seu apogeu em maio de 1968 com o movimento estudantil e, depois, nas empresas recuperadas pelos seus trabalhadores, cujo exemplo mais famoso foi o da fábrica de relógios Lip. Nos países industrializados, “[...] surgiram grupos organizados de pessoas que, com base na vivência cotidiana compartilhada, começaram a administrar diretamente a vida comunitária" (CARVALHO, 1995, p. 13).

Segundo Lallement (2007), na França a autogestão originar-se-ia de três correntes políticas. A primeira, já comentada por Carvalho, é a do marxismo crítico, num distanciamento do socialismo real e planificador. Esse movimento, liderado por sociólogos e filósofos, como Henri Lefebvre, denuncia a alienação do homem pelo sistema e reivindica a possibilidade para este de poder gerir sua própria existência, seu próprio futuro. Nesta mesma linha, encon- 
tramos intelectuais como Cornelius Castoriadis, que provém do trotskismo. A segunda corrente é a do movimento libertário, para o qual, a partir da autogestão, pode-se imaginar uma saída pacífica do capitalismo. A terceira fonte é constituída pelos cristãos de esquerda, "[...] que associam a autogestão com dois valores muito caros para eles: de um lado, a empresa é uma comunidade para a qual é preciso dar os meios da autoconstruir-se e de evoluir, de outro lado, os valores humanos devem passar antes dos valores do capital2" (LALLEMENT, 2007). Não por acaso, o marxismo crítico e os cristãos de esquerda estão também na origem da nova onda de economia solidária.

Historicamente, no Brasil a idéia de autogestão

[...] esteve presente nos programas do movimento anarquista libertário do início do século. O movimento trotskista defendia a autogestão, sobretudo em torno dos conselhos operários. [...] Na segunda metade dos anos 40, no clima de renovação do pósguerra, alguns socialistas, oriundos do PCB e do trotskismo, colocaram em pauta o debate da alternativa autogestionária. O principal exemplo é o do grupo reunido em torno do jornal Vanguarda Socialista dirigido por Mário Pedrosa, egresso do trotskismo, influenciado por Rosa Luxemburgo e pela dissidência da IV Internacional formada nos EUA(NASCIMENTO, 2000, p. 13).

\section{Autogestão e vida social}

A autogestão, como forma de governo, ressurge a cada crise do sistema político e também do sistema econômico; ou seja, a cada vez que uma estrutura está sendo questionada, a cada vez que um determinado poder perde sua legitimidade, direcionando para o que se chama de anarquia. A anarquia pode ser definida como a "negação do princípio da autoridade." Quando se recorre ao Dicionário Aurélio Eletrônico, além desta definição, há a associação do termo anarquia a situações negativas, como confusão, desordem e bagunça, criadas pela ausência de controle da situação social, econômica ou política, já que não haveria controle da mesma por uma autoridade superior.

A partir das definições já mencionadas, constata-se serem duas concepções que se afrontam: uma convencida de que os homens são capazes de se autogerir, e outra, de que sem chefias, hierarquias, não há sociedade viável. Pierre Clastres (1990, p. 17), no seu famoso livro A Sociedade contra o Estado, argumenta que o "etnocentrismo cultural do pensamento ocidental" se constitui em obstáculo epistemológico para compreender a possibilidade de existência de um poder que não seja coercitivo. Clastres (1990, p. 18) não nega a existência do po- der político, afirma até que "ele é uma necessidade inerente à vida social", mas nega que ele deva ser necessariamente violento e hierárquico. A antropologia traz a nosso conhecimento uma série de sociedades tradicionais baseadas na cooperação e na democracia, e não num sistema hierárquico e coercitivo. O autor (1990, p. 22) expõe no seu livro que é "a falta de estratificação social e de autoridade do poder que se deve reter como traço pertinente da organização política da maioria das sociedades indígenas" da América.

A discussão sobre a possibilidade de existência de uma sociedade humana sem um poder disciplinar remete a outra sobre a natureza humana. Ela seria essencialmente boa e virtuosa e levaria os homens à cooperação, ou seria essencialmente egoísta e individualista, levando os homens à concorrência e à luta entre eles, exigindo então uma autoridade superior para impor regras e punir os infratores. Barreto (2003), no seu artigo intitulado Cultura da cooperação, recorrendo a Lévi-Strauss e a antropólogos como Margaret Mead e Terry Orlick, já chamava nossa atenção sobre esse falso dilema, posto que não existe uma 'natureza' humana. Nossa especificidade como ser humano é justamente nossa capacidade de transformar a nós mesmos e ao mundo a nosso redor, nossa capacidade de construir culturas e de transformá-las. E a partir da tese de que os homens podem aprender a organizar-se sem dirigente, ou seja, de forma autogestionária, que a seguir queremos discutir.

A sociedade globalizada está tendo exitosas experiências de autogestão, entre as quais podemos citar o Fórum Social Mundial, cujas oficinas e o acampamento são autogeridos. Outro exemplo são as inúmeras redes de entidades que trabalham de maneira cooperativa, sem hierarquia. Mas é sobre a construção do processo de autogestão em empreendimentos econômicos solidários, na qual todos os trabalhadores se tornam seus administradores diretos, que vamos abordar. Neste sentido restrito, a autogestão é definida como gestão direta e democrática dos trabalhadores, nas funcões de planificacão, direção e execução.

A questão da autogestão é fundamental para caracterizar um novo tipo de cooperativismo, de associativismo, que reata com as tradições revolucionárias, revelador de uma nova concepção de democracia e de cidadania. Ela mostra uma transformação radical quanto à maneira como são pensadas as questões da fome, da miséria e da exclusão. Não se trata mais, simplesmente, de criar por decreto soluções para a geração de renda e trabalho, mas de atacar o autoritarismo social e a hierarquização das relações sociais. Não basta considerar as desigualdades como simples questões econômicas, mas analisar os aspectos políticos, sociais e culturais, historicamente presentes nas suas constituições (LECHAT, 2004). 
A autogestão é, sem dúvida, um dos conceitos mais complexos e desafiadores da economia solidária. Para o Movimento da Economia Solidária no Brasil, ele é o divisor de águas com o cooperativismo empresarial e com todas as propostas que fazem da economia solidária um simples instrumento de geração de renda e trabalho, de desenvolvimento econômico. Muitos projetos são solidários, cooperativos, mas não chegam a ser autogestionários.

Relações de trabalho autogestionárias se apresentam como antagônicas com as relações capitalistas de assalariamento, exploração dos trabalhadores, separação entre gestão e execução, entre trabalho intelectual e trabalho manual. A autogestão se opõe a práticas paternalistas, assistencialistas e clientelistas, bem como evita a corrupção dos dirigentes. A autogestão é associada a uma nova concepção de democracia participativa e de exercício efetivo da cidadania. Segundo André Valente Barreto (2003, p. 306), a autogestão é o fundamento político da cooperação.

\section{Autogestão e economia solidária no Brasil}

Nos anos cinqüenta do século 20, Paul Singer fazia parte do grupo reunido em torno do jornal Vanguarda Socialista, quando se propõs a defender a autogestão junto aos sindicatos. Em 1995, o terceiro Congresso da CNM/CUT ${ }^{3}$ decidira pela realização, no ano seguinte, de um seminário sobre o sistema de autogestão, a partir das experiências vividas pelos trabalhadores. No seminário, chamado de Empresas autogestionárias, cooperativas e estratégias da CUT, relatou-se que $54,3 \%$ das iniciativas nesta área eram de responsabilidade dos sindicatos. O professor da USP, Paul Singer e Marcos Arruda, do Instituto de Políticas Alternativas para o Cone Sul, foram convidados pela CUT para assessorar esse Seminário bem como estudos e cursos sobre questões autogestionárias.

Segundo os próprios dizeres da Associação Nacional dos Trabalhadores em Empresas de Autogestão e Participação Acionária (Anteag), esta foi criada para coordenar projetos de autogestão. A primeira empresa deve sua origem com alguns técnicos do Departamento Intersindical de Estatística e Estudos Socioeconômicos (Dieese) que, com o apoio do Sindicato dos Trabalhadores das Indústrias de Calçados de Franca-SP, iniciaram, em 1991, um trabalho pio- neiro na implantação de um projeto de autogestão na empresa de Calçados Makerly.

Foi em Criciúma, Santa Catarina, que aconteceu outra experiência seminal de autogestão. Trata-se da Cooperminas (ex-CBCA ${ }^{4}$ ), uma cooperativa autogestionária de extração de carvão. Foi lá que, em agosto de 1993, o Instituto de Políticas Alternativas para o Cone Sul (PACS) ${ }^{5}$ e outras entidades, entre as quais o Sindicato dos Mineiros, articularam o primeiro seminário sobre autogestão. Esta experiência foi apresentada no primeiro Fórum Social Mundial e nas publicações da Anteag.

A Agência de Desenvolvimento Social (ADS), criada em 1998 por iniciativa da CUT em parceria com a Unitrabalho e o Dieese, assessora, por sua vez, cooperativas rurais e urbanas na tentativa de criar complexos cooperativados. Seu objetivo é implementar cadeias produtivas, constituindo um plano conjunto de produção e comercialização entre os diversos empreendimentos, interligando-os de forma a fortalecê-los para que possam competir no mercado. No seu site, www.ads.org.br, podemos ler: "Todas as atividades serão orientadas metodologicamente para a promoção de projetos coerentes com os princípios da autogestão, da economia solidária e do desenvolvimento sustentável." Mais recentemente, a União e Solidariedade das Cooperativas Empreendimentos de Economia Social do Brasil (Unisol-Brasil) organizou-se para

[...] representar e articular, de forma ampla e transparente, as cooperativas, associações e outros empreendimentos autogestionários da economia solidária, resgatando e promovendo a intercooperação, a igualdade social e econômica, a dignidade humana e o desenvolvimento sustentável (UNISOLBRASIL, 2007).

Muito já foi escrito no Brasil sobre autogestão e economia solidária. Em 1998, a Universidade Estadual Paulista (UNESP) realizava seu II Simpósio Nacional Universidade-Empresa sobre Autogestão e Participação, que deu origem a uma publicação sobre esta temática. Entre os objetivos do simpósio, podemos citar a necessidade de consolidar e avaliar os estudos e experiências autogestionárias no Brasil e impulsionar linhas de pesquisa sobre relações de trabalho e autogestão. Só no ano 2000, publicaram-se pelo menos três livros com esta 
palavra no título (ANTEAG, NASCIMENTO, SINGER; SOUZA, 2000).

No primeiro Fórum Social Mundial, de 28 a 29 de janeiro de 2001, foi organizada a oficina Economia solidária e autogestão: novas formas de geração de trabalho e renda. De lá para cá inúmeros foram os artigos e comunicações em eventos que tratam da autogestão, que, segundo indicam todas as pesquisas e escritos, é a meta mais difícil de ser atingida.

Segundo Lallement (2007), a autogestão teria sido realizada mais na ordem do simbólico do que na ordem do real, mesmo que ela se encontre no programa de alguns movimentos sociais. No Brasil, como já observaram Guerra (2002), Lechat (2004), França Filho e Laville (2004) e outros, a economia solidária adquire feições mais radicais que em outros países e um discurso marcadamente mais político.

\section{Autogestão e incubação}

A seguir, queremos mostrar como na prática a equipe da Incubadora de Economia Solidária da Universidade Regional do Noroeste do Estado do Rio Grande do Sul (Unijuí) pratica a autogestão e tenta implementá-la nos empreendimentos econômicos solidários que ela assessora. Não basta querer implantar a autogestão, ainda é preciso criar as condições para sua efetivação. A autogestão não é uma qualidade que um empreendimento possua ou não, é um processo em constante gestação que pode sofrer avanços, mas também retrocessos. Aprende-se o que é autogestão, praticando-a. É um processo que exige vigilância.

Está grafada em todos os documentos, que explicitam a estruturação da incubadora como um projeto de extensão universitária, a opção de, pela sua atuação, estar a serviço da promoção da cidadania, do trabalho e da inclusão social, respaldada pelos princípios e valores já consolidados da economia solidária, ou seja: cooperação, autogestão, solidariedade, valorização do trabalhador e desenvolvimento sustentável. Significa, na verdade, o propósito de trabalhar na criação ou compreensão de outra cultura de vida e de convivência que não é a hegemônica na sociedade. Entende-se, então, que se está propondo a contra-hegemonia, cuja metodologia de ação requer que se tenha como eixo transversal do processo de trabalho a formação.

Importante também destacar que a incubadora propôs, desde o início, alguns referenciais para a elaboração da metodologia, que são os cinco eixos orientadores: "incubação de empreendimentos, promoção, divulgação e articulação da economia solidária, formação de agentes em economia solidária e criação de redes de comercialização" (LECHAT; VAN DER SAND; JULIANI, 2003).
Neste sentido, coerente com os valores e princípios desse movimento e suficiente fundamentação teórica, a equipe proponente do projeto fez a escolha de paradigma que reconhece na atuação profissional a necessária integração dos conhecimentos. Daí a constituição de uma equipe multidisciplinar de profissionais com orientação de atuação integrada e com foco no fortalecimento do coletivo em todas as etapas do processo: planejamento, acompanhamento da execução das atividades, avaliação aberta e democrática das consequiências das ações desenvolvidas e do desempenho da equipe e dos sujeitos da interação no trabalho dos e com os empreendimentos, bem como com as novas decisões. Outra orientação pedagógica e politicamente relevante foi a de se fazer o esforço de registrar todos os momentos da ação e de socializar a produção teórica, quando ela é base para a operatividade dos envolvidos ou quando se faz latente durante ou após determinados aspectos do processo. Daí resultou a constituição da memória da incubadora, que integra os elementos burocráticos como recursos para a efetivação das dimensões descritiva, teórica e discursiva como as de maior importância para a fundamentação da continuidade dos propósitos e da intervenção junto aos grupos por ela contemplados.

A metodologia recebeu, portanto, desde o início uma atenção muito especial da coordenação do projeto e da equipe, por se constituir no desafio central tanto para a atuação interna à incubadora, quanto para o cumprimento dos fins a que se destinava o trabalho. Assim, as relações entre as ações internas e as ações externas na construção da metodologia, alcançam e assumem sua real importância, para a qual a equipe que compôs essa incubadora estava atenta desde a estruturação do projeto.

Outro traço que se encontra registrado como fator de potencial necessário à construção da metodologia de incubação, nas suas três fases, é a comunicação. E, para tanto, o domínio de algumas linguagens precisava ser garantido progressivamente, tanto pela equipe assessora, quanto pelos membros dos empreendimentos. A democratização nas comunicações precisou ser pensada com bastante empenho e convicção, impondo-se, também, como imperativo da construção, de uma inteligência ou intelectualidade capaz de conformar posturas de diálogo, de respeito aos saberes da experiência, aos saberes tácitos, à cultura do excluído, que em muitos momentos adquire o tônus de um 'mundo independente', cuja única preocupação é preservar a vida, apesar das condições adversas na dinâmica social de seu entorno.

Por outro lado, cuidou-se, na elaboração do projeto, de se manter coerência com o entendimento de que é possível valorizar e articular os saberes do senso comum com a apropriação do conhecimento das ci- 
ências, principalmente porque todos os seres humanos têm o direito de deles se apropriarem para tornar sua vida mais produtiva e digna. As metas que propunham a divulgação e a articulação do movimento da economia solidária indicavam a utilização de recursos como folders, banners, boletins informativos, a mídia, comunicações em eventos de diversas naturezas, numa clara demonstração da crença de que qualquer trabalhador está habilitado a capacitar-se para o uso desses recursos. Embora de uso corrente na sociedade letrada e nas organizações identificadas com a lógica capitalista, podem compor o percurso de outra lógica.

Sabe-se que tudo tem seu tempo de acontecer. Mas sabe-se, também, que o tempo não se reduz ao tic-tac físico de um relógio, mas é de construção social e durabilidade decidida pelos prazos que se estabelecem no âmbito mais das disposições e condições objetivas e subjetivas para atuação, do que só do cronograma a ser cumprido. Nele cabe pouco ou muito, dependendo de como os sujeitos se orientam e de como sua experiência vai lhes facultando otimizar as potencialidades visualizadas. Por isso, no projeto da incubadora, o tempo foi pensado como elemento no qual a metodologia deveria encontrar o fluxo necessário para sua explicitação conseqüente em seus resultados.

Por fim, a participação em fóruns de discussão sobre o objeto que caracteriza o trabalho da incubadora consta como outro e importante elemento de auxílio na conformação da metodologia de incubação, no reconhecimento de que a socialização de experiências e saberes tem lugar destacado nos processos educativo e formativo dos sujeitos individuais e coletivos. Há uma compreensão bastante homogênea na explicitação de que os valores fundantes da economia solidária são, também, fundantes da adequada metodologia para o trabalho de incubação. A autogestão e a democracia dinamizam efetivamente as competências dos que se integram a esse movimento. Esses valores garantem a postura de discussão aberta, franca e sistemática, sem qualquer possibilidade de coação ou constrangimento, que, por isso, tornou-se processo pedagógico de formação, fortalecendo a equipe e dando-lhe confiança e segurança para atuar no cotidiano diverso dos empreendimentos. Outro efeito dessa construção, reconhecido pelos profissionais da incubação, que merece destaque é o do crescimento mútuo propiciado pelas constantes trocas de saberes com o devido respeito às práticas e visões ou concepções de que são portadores os componentes do grupo de organização e condução das ações. A forma de atuação junto aos empreendimentos, respaldada pelas aprendizagens auferidas nas reuniões semanais, nos fóruns, nas leituras, na paciência pedagógica da espera (sem parar) de que o outro se sinta esclarecido, evidenciou o diferencial na diferença, no jeito de ser e agir de cada um dos empreendimentos. A crença de que uma metodologia de trabalho, consoante com o que se pensa e ensina no sentido de fazer o rompimento da lógica da competição e do lucro venal ou 'loas' individuais, tem lugar, sim, quando se faz o enfrentamento das tensões e o aproveitamento das oportunidades com sabedoria e persistência. Vygotski (1998) entende que o homem constrói hipóteses sobre si mesmo e sobre seu contexto de vida, que o levam à realização de determinadas ações. $\mathrm{O}$ processo de mudança ocorre porque, a partir dessas ações, o sujeito é impelido a levantar várias e novas hipóteses que, por sua vez, encaminham outras ações que modificam as circunstâncias e a forma do sujeito pensar e agir. São as aprendizagens se fazendo, inclusive a de como é possível se aprender e organizar novas maneiras de agir. Dessa forma o homem constrói o poder de autogestão da sua vida.

No caso da construção da metodologia de incubação de empreendimentos na região focada pela incubadora, as práticas históricas de produção têm a cooperação como um hábito que pode ser potencializado pelos empreendimentos, passando a ser estratégia. Por quê? Porque facilita a inclusão desses empreendimentos numa rede sociopolítica e econômica, construída na base, com repercussão nos órgãos de direção e/ou comando e uma mudança de cultura (pela intencionalidade).

O caminho dessa aprendizagem de sistematizar uma proposta metodológica de incubação mostrou que há "variações", provocadas pelas "políticas definidas pelo governo federal, pelas análises da conjuntura do Estado frente ao cenário nacional e internacional" (LECHAT et al, 2006) e pelas condições institucionais da entidade executora. A produção dos avanços necessários aponta para a presença substantiva de contrapartida do Poder Público, no respeito à autonomia das entidades. Compreende-se, hoje, que são fortes os motivos existentes para desagregar o grupo e desanimar empreendimentos. Essas tensões desafiam, ainda, para se produzir tempo e capacidade de teorização das práticas de incubação rumo à definição das variáveis, dos princípios e das argumentações que dêem sustentação à metodologia com a qual se pode e se deseja trabalhar.

Quais atividades precisam ser mantidas e consolidadas? Como organizar o tempo segundo a natureza das demandas e o grau de complexidade que apresentam? Como fazer a gestão dos encaminhamentos e das pessoas que as assumem? São indagações que se construíram na percepção dos membros da equipe e que são elementos importantes na conscientização frente ao compromisso e à necessidade de permanente reflexão para práticas sempre mais profundamente esclarecidas. Os registros analisados revelam a inquietação com essas questões pela necessidade sentida de que é preciso manter unido o grupo responsável 
pelo empreendimento, buscar profissionalizar seu trabalho, manter vivo um ideal ou objetivos compreensíveis por todos os associados.

A continuidade do processo de visitação aos empreendimentos, articulada com reuniões periódicas, mostrou-se produtiva, bem como o aproveitamento do maior número possível de oportunidades para que os empreendimentos se façam presentes e se articulem entre si e com a sociedade mais ampla. Aí se viabilizam, de modo progressivo, espaços de expressão, de participação e de crescimento pessoal e dos grupos. Na medida em que cada pessoa se fortalece, passa a ser vetor de fortalecimento de seu grupo.

Os recursos utilizados na realização das várias atividades do projeto contribuem para que a metodologia seja conseqüente aos fins que persegue. Tecnologias agilizando a comunicação entre os diversos atores (empreendimentos, apoiadores, simpatizantes, assessores), que os capacitam para o trabalho e a participação, que os colocam no circuito mais amplo do movimento, podem diminuir distâncias invisíveis e gigantescas, por isso são consideradas relevantes na construção da metodologia.

O portfólio, os cadernos da série Economia Solidária, os boletins informativos, os releases para os jornais, os informes eletrônicos, os relatórios, os resumos e outros instrumentos de apoio e de divulgação, assumiram rapidamente o status de estratégias de reflexão, de fundamentação para colocar a economia solidária no debate entre outros temas da sociedade local e regional, principalmente. Esta mostrou-se ser mais uma direção que uma metodologia de incubação de EES precisa considerar sempre. A visibilidade e a compreensão dessa forma de geração de trabalho e renda questionaram a sociedade sobre valores e sustentabilidade da vida em harmonia, mobilizando-a para parcerias e ações coletivas. Embora na maior parte das vezes os apoios fossem pontuais, é incontestável que novas atitudes se explicitaram em relação aos trabalhadores organizados em associações e/ou cooperativas e em relação a hábitos de consumo e de cuidados com o ambiente. Por exemplo, Morin (2000, p. 86-87), tratando sobre as incertezas e a ecologia da ação, assim se expressa:

Temos, às vezes, a impressão de que a acão simplifica, pois em uma alternativa decide-se, escolhe-se. Entretanto, a ação é decisão, escolha, mas é também uma aposta. [...] Aqui intervém a noção de ecologia da ação. Tão logo um indivíduo empreende uma ação, [...] esta começa a escapar de suas intenções. Esta ação entra em um universo de interações e é finalmente o meio que se apossa dela. A ecologia da ação é levar em consideração a complexidade que ela supõe, ou seja, o aleatório, acaso, iniciativa, decisão, inesperado, imprevisto, consciência de derivas e transformações.
Isto posto, parece pertinente acreditar que o esforço de construção da metodologia pela equipe da incubadora, ao lado dos empreendimentos e apoiadores, coaduna-se com as explicitações de Marques (1990, 1992, 1995), em vários de seus textos. Para ele, a metodologia significa a operacionalização de uma pedagogia que se realiza pela:

a) mediação entre a experiência como leitura operativa das práticas formativas e como tematização e interpretação das mesmas;

b) continuidade das práticas, entendida como regularidade e recursividade educativas através das instituições específicas, no caso os empreendimentos de economia solidária e a incubadora, onde se organizam as estratégias de manutenção dos estímulos e do controle das condições da ação coletiva (autogestão), e

c) consolidação das práticas pela construção da compreensão sobre objetivos comuns e negociações sobre os caminhos a trilhar, no interior dos coletivos ou dos grupos, pela livre e comprometida participação de todos os envolvidos.

Disso decorre a proposição de que são três os cenários em que devem atuar as dimensões constitutivas de uma metodologia, quais sejam: o nível das práticas educativas diretas (assessorias); o nível das práticas instituintes da organização através do planejamento das ações, discutido e validado por todos os integrantes dessa organização; e o nível das práticas coletivas, como movimento de condução da proposta de ação e do empreendimento em si.

Campos (2006) propõe uma reflexão sobre os termos incubar e incubação, sobre a natureza de um pedido e de uma demanda, alertando que em um pedido nem sempre há uma demanda e em uma necessidade nem sempre há um desejo. E aguça sua problematização indagando: "E nós - Incubadora de Economia Solidária - não estaremos também em estado de incubação? Possuímos algo em estado latente?", associando à definição de que incubar e incubação é "possuir em estado latente".

\section{Considerações finais}

Como escreve Boaventura de Sousa Santos (2002, p.14), “o que está em causa é a própria reinvenção da emancipação social.” Historicamente os trabalhadores implantaram a autogestão em situações revolucionárias de mudanças políticas. Hoje é uma revolução cultural, política e socioeconômica que a proposta autogestionária da economia solidária se propõe a realizar. Ao contrário do que acontece no sistema capitalista e na política neoliberal, o movimento da economia solidária visa edificar uma sociedade 
voltada para a emancipação do ser humano. Um ser humano integral com sua inteligência, suas capacidades, seus desejos e necessidades, cujas qualidades individuais são valorizadas na medida em que são colocadas ao serviço da coletividade. A formação deste trabalhador associado deve ultrapassar a dicotomia do pensar e do agir, ultrapassar a dimensão do empreendimento, entender o contexto político e socioambiental mais amplo no qual se situa e trazer a compreensão de que somos o produto de uma longa história de dominação e de exploração. Por todas essas razões, como o fermento na massa, o caminho da transformação é lento, mas possível.

Da tentativa de sistematização feita sobre a metodologia de incubação, infere-se ser fundamental que esse "possuir em estado latente" não desapareça, mas que seja tambor para a reflexão permanente das práticas. Uma metodologia de incubação precisa ser grávida de disposição, de teorização e de persistência para encarar a diversidade própria das realidades que se apresentam nos empreendimentos, e que o tempo também produz, na medida em que as aprendizagens vão se realizando; afinal, "a vida é, basicamente, uma persistência de processos de aprendizagem", conforme ensina o professor Hugo Assmann (1998, p. 22).

O fortalecimento da unidade teoria-prática permanece como desafio, por congruência com a ação educativa de que está encharcada a prática da incubação. A necessidade de investimento na fundamentação teórica para todos se apresenta como a possibilitação de um ágil desempenho, com mais produtividade, junto aos empreendimentos e a outros espaços de ação da economia solidária.

\section{Referências}

ALBUQUERQUE, P. P. de. Autogestão. In: CATTANI, A. D. (Org.). A outra economia. Porto Alegre: Veraz Editores, 2003. p. 20-25.

ANTEAG. Autogestão, construindo uma nova cultura nas relações de trabalho. São Paulo: Espalhafato Comunicação e Produção, 2000.

ASSMANN, H. Reencantar a educação: rumo à sociedade aprendente. Petrópolis: Vozes, 1998.

BARRETO, A. V. Cultura da cooperação: subsídios para uma economia solidária. In: SOUZA, A. R. et al. (Org.). Uma outra economia é possível. São Paulo: Contexto, 2003. p. 287-314.

CAMPOS, Í. F. A. Questões para incubadores. Ijuí, 7 nov. 2006. Texto avulso.
CARVALHO, N. V. de. Autogestão. O nascimento das ONGs. São Paulo: Brasiliense, 1995.

CLASTRES, P. A sociedade contra o Estado. Rio de Janeiro: Francisco Alves, 1990.

FARIA, J. H. de. Comissões de fábrica: poder e trabalho nas unidades produtivas. Curitiba: Criar Edições, 1987.

FRANÇA FILHO, G. C.; LAVILLE, J.-L. Economia solidária, uma abordagem internacional. Porto Alegre: UFRGS, 2004.

GUERRA, P. Socioeconomía de la solidariedad. Montevideo: Editorial Nordan-Comunidad, 2002.

GUIMARÃES, V. N. Novas tecnologias de produção de base microeletrônica e democracia industrial: estudo comparativo de casos na indústria mecânica de Santa Catarina. 1995. Tese (Doutorado em Engenharia de Produção). Universidade Federal de Santa Catarina, Florianópolis, 1995.

LALLEMENT, M. L'autogestion, une histoire contrariée. Sciences Humaines, n. 187, nov. 2007. Disponível em: $<$ http://www.scienceshumaines.com $>$. Acesso em: 19 out. 2007.

LECHAT, N. M. P.; VAN DER SAND, A.; JULIANI, L. Projeto PRONINC Empreender: implantação de uma incubadora de economia solidária na Unijuí. Ijuí: Unijuí, 2003.

LECHAT, N. M. P. Trajetórias intelectuais e o campo da Economia Solidária no Brasil. 2004. Tese (Doutorado em Ciências Sociais) - Universidade Estadual de Campinas, Campinas, 2004.

et al. Incubadora de Economia Solidária e Desenvolvimento Regional Sustentável da Unijuí In: CONGRESSO BRASILEIRO DE EXTENSÃO UNIVERSITÁRIA, 3, 2006. Florianópolis. Anais ... Florianópolis: UFCS, 2006. v. 1. CD ROM.

et al. Gestão de empreendimentos econômicos solidários na Região Noroeste do Rio Grande do Sul. Civitas, Revista de Ciências Sociais. Porto Alegre: PUC, v. 7, n. 1, p. 175-194, jan./jun. 2007.

MARQUES, M. O. Pedagogia: a ciência do educador. Ijuí: Editora Unijuí, 1990.

A formação do profissional da educação. Ijuí: Editora Unijuí, 1992.

A aprendizagem na mediação social do aprendido e da docência. Ijuí: Editora Unijuí, 1995. 
MORIN, E. Os sete saberes necessários à educação do futuro. São Paulo: Cortez/Unesco, 2000.

NASCIMENTO, C. Autogestão e economia solidária. Outros valores, Cadernos da cidade do futuro, Florianópolis. v. 1, n. 2, 2000.

SINGER, P.; SOUZA, A. R. de. A economia solidária no Brasil: a autogestão como resposta ao desemprego. São Paulo: Contexto, 2000.

UNISOL-BRASIL. Missão. Disponível em: < www.unisolbrasil.org.br>. Acesso em: out. 2007.

VYGOTSKI, L. S. A formação social da mente. São Paulo: Martins Fontes, 1998.

\section{Notas}

1 Tradução da autora.

2 Tradução da autora.

3 CNM/CUT: Confederação Nacional dos Metalúrgicos/ Central Única dos Trabalhadores.

4 Companhia Brasileira Carbonífera de Araranguá.

5 Localizado no Rio de Janeiro.

\section{Noëlle M. P. Lechat}

Doutora em Ciências Sociais pela Unicamp Professora titular da Universidade Regional do Noroeste do Estado do Rio Grande do Sul (Unijuí) Coordenadora da Incubadora de Economia Solidária da Unijuí

\section{Eronita da Silva Barcelos}

Pedagoga

Professora titular da Unijuí

Assessora pedagógica da Incubadora de Economia Solidária da Unijuí

\section{Unijuí}

Rua do Comércio, 3000

Prédio Beta

Universitário

Ijuí - Rio Grande do Sul

CEP: 98700-000 